\title{
UNPASSIVATED HIGH OPERATING TEMPERATURE GaInAsSb INFRARED PHOTODETECTOR GROWN ON GaAs SUBSTRATE
}

\author{
Ŭ̆ur SERINCAN ${ }^{1, *}$, Mehmet ERKUŞ $^{1}$ and Onur ŞENEL ${ }^{1}$ \\ ${ }^{1}$ Nanoboyut Research Laboratory, Department of Physics, Faculty of Science, Anadolu University, 26470 Eskişehir, Turkey
}

\begin{abstract}
$\mathrm{Ga}_{0.87} \mathrm{In}_{0.13} \mathrm{As}_{0.4} \mathrm{Sb}_{0.96}$ photodiode structure was grown on semi-insulating 4" GaAs substrate by molecular beam epitaxy. The composition, crystal quality and dislocation density of epilayers were determined by high resolution X-ray diffraction rocking curve measurements. The threading dislocation density of the photodetector structure was calculated from the rotational broadening as $\sim 2.5 \times 10^{8} \mathrm{~cm}^{-2}$. The cutoff wavelength and the peak responsivity of the photodetector were determined as around $2.15 \mu \mathrm{m}$ and $0.08 \mathrm{~A} / \mathrm{W}$ at $300 \mathrm{~K}$, respectively. By applying reverse bias $(-100 \mathrm{mV})$ the responsivity value of the photodetector increases more than an order $(\sim 0.96 \mathrm{~A} / \mathrm{W})$ which is the best value reported up to now. Those results indicate that although there is a large lattice mismatch $(\sim 8.4 \%)$ between GaAs substrate and the photodetector structure, an acceptable photodetector performance was achieved which is important for reducing photodetector costs.
\end{abstract}

Keywords: MBE, GaInAsSb, HRXRD, Photodetector

\section{INTRODUCTION}

Infrared photodetectors operated at 2-3 $\mu \mathrm{m}$ wavelength have received significant interest in recent years due their possible applications such as near infrared spectroscopy, gas sensing, chemical process monitoring, photovoltaics and astronomy [1-3]. For infrared detection, the commonly used material $\mathrm{HgCdTe}$ (MCT) involves serious technical problems such as the difficulty in growing at large scale and lattice/surface/interface stabilities [4]. It also provides a relatively low tolerance to elevated temperatures because of high diffusion rates in the material [5]. On the other hand, $\mathrm{Ga}_{x} \mathrm{In}_{1-\mathrm{x}} \mathrm{As}_{\mathrm{y}} \mathrm{Sb}_{1-\mathrm{y}}$ alloys offer covalent bonding which makes them more stable and a reliable replacement for MCT, especially in nearand mid- infrared regions [6-10]. Moreover, band gap of $\mathrm{Ga}_{x} \mathrm{In}_{1-\mathrm{x}} \mathrm{As}_{\mathrm{y}} \mathrm{Sb}_{1-\mathrm{y}}$ alloys can be adjusted as desired between 1.7 and $4.9 \mu \mathrm{m}$ by changing the concentrations of the constituent elements while remaining lattice matched to a GaSb substrate [6]. For this reason, $\mathrm{Ga}_{\mathrm{x}} \mathrm{In}_{1-\mathrm{x}} \mathrm{As}_{\mathrm{y}} \mathrm{Sb}_{1-\mathrm{y}}$ photodetector structures are traditionally grown on GaSb substrates. However, GaSb substrate suffers from high free carrier absorption losses at infrared regions and it has relatively high cost compared to $\mathrm{Si}$ and $\mathrm{GaAs}$ substrates [7]. Besides, GaSb substrate is not yet abundantly available in diameters larger than 4 inch. Owing to those limitations, GaAs substrates have been preferred for the growth of Sb-based structures.

In this study, we present high crystalline quality $\mathrm{Ga}_{0.87} \mathrm{In}_{0.13} \mathrm{As}_{0.4} \mathrm{Sb}_{0.96}$ photodetector grown on GaAs substrate. In order to improve the crystal quality of the detector a GaSb transition layer was applied between the GaAs substrate and photodetector structure. The detector structure was monitored in terms of structural, optical and electrical features. The composition and threading dislocation densities of samples were determined by high resolution X-ray diffraction (HRXRD) measurements. The zero bias resistance-area product $\left(\mathrm{R}_{0} \mathrm{~A}\right)$ was extracted from dark current curve at zero bias. In order to identify the band gap energy of the photodetector structure, temperature dependent photoluminescence (PL) measurements were conducted and the cutoff wavelength of the detector was inferred from spectral photoresponse measurements.

*Corresponding Author:userincan@anadolu.edu.tr 


\section{EXPERIMENTAL}

$\mathrm{Ga}_{0.87} \mathrm{In}_{0.13} \mathrm{As}_{0.4} \mathrm{Sb}_{0.96}$ photodetector structure was grown on epi-ready semi-insulating GaAs (100) substrate using Veeco GEN20MC solid-source MBE system equipped with valved arsenic (As)/antimony ( $\mathrm{Sb}$ ) cracker cells and gallium $(\mathrm{Ga}) /$ indium ( $\mathrm{In})$ dual filament cells. The cracker temperatures were kept at $900{ }^{\circ} \mathrm{C}$ for both $\mathrm{As}$ and $\mathrm{Sb}$ effusion cells: $\mathrm{As}_{2}$ and $\mathrm{Sb}_{2}$ were used as group-V fluxes. The beam equivalent pressure (BEP) was measured by an ionization gauge at the back of the substrate manipulator, when it was rotated into the direct beam path. For the binary compounds, the BEPs were set to be $6.1 \times 10^{-8}, 1.1 \times 10^{-6}$ and $5.8 \times 10^{-7}$ Torr for $\mathrm{Ga}$, As and $\mathrm{Sb}$, respectively. For the quaternary compound, the BEPs were set to be $6.1 \times 10^{-8}, 2.3 \times 10^{-8}, 8.2 \times 10^{-8}$ and $5.8 \times 10^{-7}$ Torr for Ga, In, As and $\mathrm{Sb}$, respectively. The base pressure of the MBE system was $7 \times 10^{-11}$ Torr at the stand by temperature of the effusion cells. Substrate temperature was measured by using an IRCON pyrometer which was calibrated against the GaSb $(1 \times 3) \rightarrow(2 \times 5)$ surface reconstruction transition [11]. Prior to the growth, native oxide was desorbed from the GaAs surface under $\mathrm{As}_{2}$ overpressure nearly $10 \mathrm{~min}$ at 605 ${ }^{\circ} \mathrm{C}$ and the desorption process was monitored by the reflection high-energy electron diffraction (not shown here). Following oxide desorption, around $530 \mathrm{~nm}$ thick Be-doped GaAs buffer layer was grown with a growth rate of $0.58 \mathrm{ML} / \mathrm{s}$ at $585{ }^{\circ} \mathrm{C}$. For the transition layer, the temperature was reduced to 498 ${ }^{\circ} \mathrm{C}$ under $\mathrm{As}_{2}$ flux and a $\mathrm{GaSb}$ transition layer around $1000 \mathrm{~nm}$ was grown with a growth rate of 0.61 $\mathrm{ML} / \mathrm{s}$. During the transition from GaAs to GaSb layer the Sb valve and shutter were opened immediately after closing the As valve and shutter. Finally, the photodetector layers were grown with a growth rate of $0.65 \mathrm{ML} / \mathrm{s}$ at $460{ }^{\circ} \mathrm{C}$. The top contact and absorber layers were doped with Si to a level of $1 \times 10^{18}$ and $1 \times 10^{16} \mathrm{~cm}^{-3}$, respectively where the bottom contact layer was doped with Be to a level of $1 \times 10^{18} \mathrm{~cm}^{-3}$. The absorber layer was doped with $\mathrm{Si}$ to promote intrinsic layer since $\mathrm{Ga}_{\mathrm{x}} \mathrm{In}_{1-\mathrm{x}} \mathrm{As}_{\mathrm{y}} \mathrm{Sb}_{1-\mathrm{y}}$ layer is unintentionally p-type especially for high $\mathrm{Ga}$ and $\mathrm{Sb}$ concentration [8]. The complete photodetector structure is illustrated in Figure 1.

\begin{tabular}{|l|}
\hline Top Contact $(1330 \mathrm{~nm})-\mathrm{Ga}_{0.87} \mathrm{In}_{0.13} \mathrm{As}_{0.04} \mathrm{Sb}_{0.96}-\mathrm{Si}: 1 \times 10^{18} \mathrm{~cm}^{-3}$ \\
\hline Absorber Layer $(1400 \mathrm{~nm})-\mathrm{Ga}_{0.87} \mathrm{In}_{0.13} \mathrm{As}_{0.04} \mathrm{Sb}_{0.96}-\mathrm{Si}: 1 \times 10^{16} \mathrm{~cm}^{-3}$ \\
\hline Bottom Contact $(1330 \mathrm{~nm})-\mathrm{Ga}_{0.87} \mathrm{In}_{0.13} \mathrm{As}_{0.04} \mathrm{Sb}_{0.96}-\mathrm{Be}: 1 \times 10^{18} \mathrm{~cm}^{-3}$ \\
\hline Transition Layer $(1080 \mathrm{~nm})-\mathrm{GaSb}-\mathrm{Be}: 1 \times 10^{17} \mathrm{~cm}^{-3}$ \\
\hline Buffer $(530 \mathrm{~nm})-\mathrm{GaAs}-\mathrm{Be}: 1 \times 10^{17} \mathrm{~cm}^{-3}$ \\
\hline Substrate - 4 inch SI GaAs \\
\hline
\end{tabular}

Figure 1. The schematic view of grown photodetector structure

In order to determine the structural properties of the photodetector, HRXRD rocking curve (RC) measurements including symmetric and asymmetric planes were performed by PANalytical X'Pert PRO $\mathrm{X}$-ray diffraction system at room temperature. The measurements were obtained using the $\mathrm{Cu} \mathrm{K} \alpha$ radiation and a four bounce Ge 400 hybrid monochromator setup with a fixed divergence slit of $1 / 2^{\circ}$. The HRXRD RC measurements were conducted at a voltage of $45 \mathrm{kV}$ and a current of $40 \mathrm{~mA}$.

For optoelectronic measurements, the mesa structures with a surface area of $0.16 \mathrm{~mm}^{2}$ were fabricated using conventional photolithographic steps where $\mathrm{C}_{6} \mathrm{H}_{8} \mathrm{O}_{7}: \mathrm{H}_{3} \mathrm{PO}_{4}: \mathrm{H}_{2} \mathrm{O}_{2}: \mathrm{H}_{2} \mathrm{O}$ (55:3:5:220 ml) solution was used for the wet etching process. The top and bottom ohmic contacts consist of $50 \mathrm{~nm} \mathrm{Ti}, 50 \mathrm{~nm} \mathrm{Pt}$ and $300 \mathrm{~nm} \mathrm{Au}$ layers and no passivation or antireflective coating were applied for the fabricated devices. The spectral photoresponse was measured by using a Bruker Vertex $80 \mathrm{~V}$ Fourier transform infrared spectrometer equipped with photoluminescence (PL) module. The low temperature measurements were performed by using a closed-cycle helium cryostat with $\mathrm{ZnSe}$ optical window between 10 and $170 \mathrm{~K}$ with $10 \mathrm{~K}$ steps under $532 \mathrm{~nm}$ excitation source. In order to be comparable with 
the low temperature measurements, the room temperature measurements were conducted with the same configuration and the setup as well. A pre-calibrated black body was used for spectral responsivity measurement and the black body operation temperature and optical chopper's frequency were kept at $1000{ }^{\circ} \mathrm{C}$ and $93 \mathrm{~Hz}$, respectively.

\section{RESULTS and DISCUSSION}

In Figure 2, HRXRD (004) measurement of the sample is presented. The peaks observed at the diffraction angles $30.23,30.38$ and $33.05^{\circ}$ are corresponding to the $\mathrm{Ga}_{0.87} \mathrm{In}_{0.13} \mathrm{As}_{0.04} \mathrm{Sb}_{0.96}$ layers, $\mathrm{GaSb}$ layer and GaAs substrate, respectively. From the HRXRD curve, the full with at half maximum (FWHM) value of the $\mathrm{Ga}_{0.87} \mathrm{In}_{0.13} \mathrm{As}_{0.04} \mathrm{Sb}_{0.96}$ layers were determined as 260 arcsec where the FWHM of the GaSb layer was calculated as 206 arcsec. These values depict that although there is a large lattice mismatch between $\mathrm{Ga}_{0.87} \mathrm{In}_{0.13} \mathrm{As}_{0.04} \mathrm{Sb}_{0.96}$ and GaAs ( 8.4\%) high quality photodetector structure was successfully grown on GaAs by using the GaSb transition layer which is a well-known method to compensate the effects of the large lattice mismatch in these structures $[7,12]$.

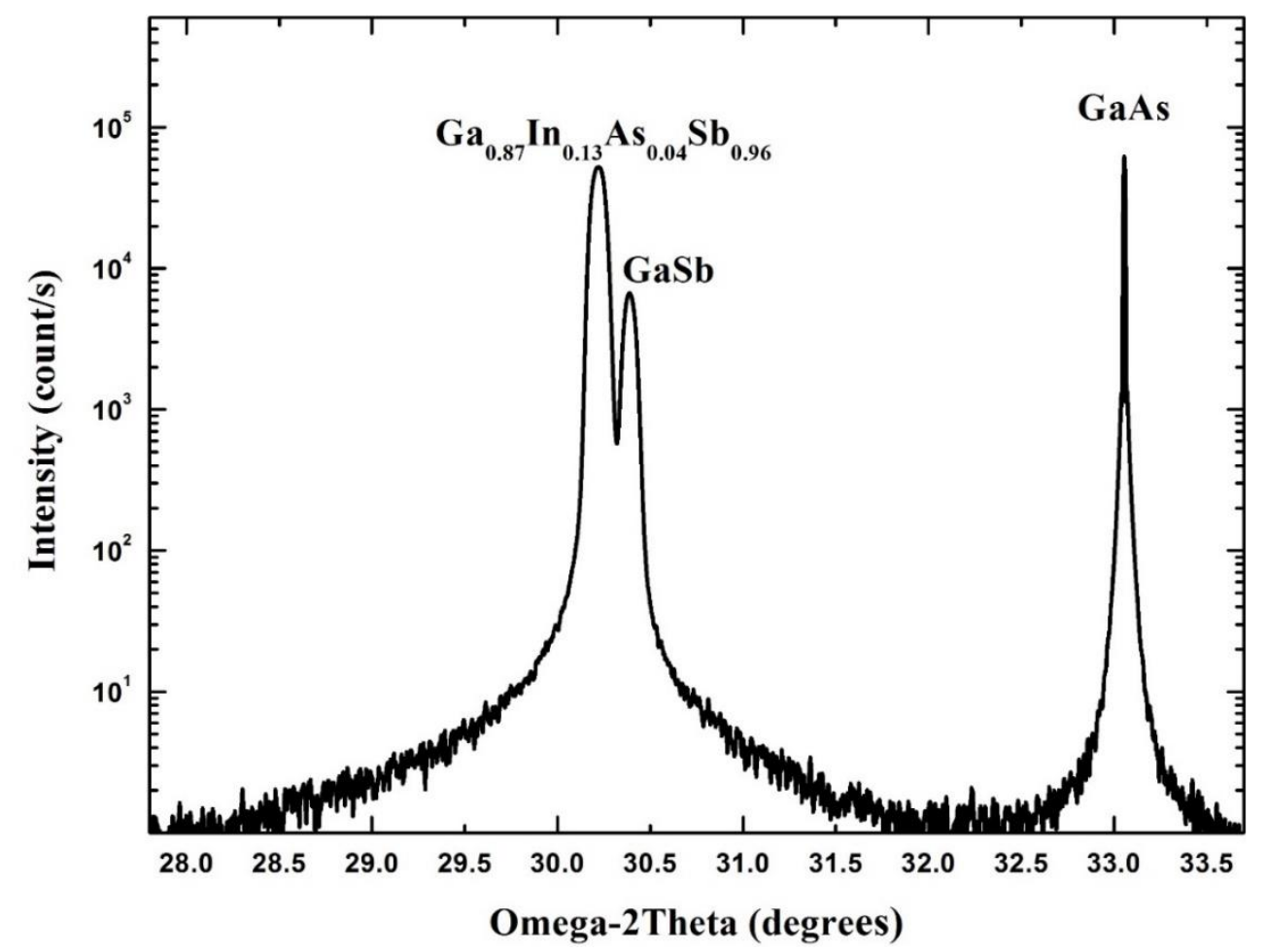

Figure 2. HRXRD (004) curve of the photodetector structure

In III-V compound semiconductors, dislocations and point defects lead to the reduction of carrier lifetime and mobility through the well-known Shockley-Read-Hall process and Auger recombination [13]. Therefore, the performance of the photodetector is directly related with the density of dislocations and point defects in the epilayer and it is crucial to determine those values for a better understanding of detector performance. Dislocation densities can be determined via destructive techniques such as transmission electron microscopy and etch pit density. On the other hand, HRXRD is simple, contactless, non-destructive and highly effective technique which can accurately determine the threading dislocation densities in the range from $10^{5}$ to $10^{9} \mathrm{~cm}^{-2}$ [14]. As proposed by Ayers [14], threading dislocation densities in semiconductor crystals can be determined by using the Eq. (1).

$$
\beta^{2} \approx \mathrm{K}_{\alpha}+\mathrm{K}_{\varepsilon} \tan ^{2} \theta
$$


In Eq. (1), $\beta$ is the FWHM value of the HRXRD RC and $\mathrm{K}_{\alpha}$ and $\mathrm{K}_{\varepsilon}$ can be obtained from the plot of $\beta^{2}$ versus $\tan ^{2} \theta$ where $K_{\alpha}$ is the intercept and $K_{\varepsilon}$ is the slope of the plot. Then, the threading dislocation density can be calculated as

$$
\mathrm{D}=\frac{\mathrm{K}_{\alpha}}{4.36 \mathrm{~b}^{2}}
$$

where $b$ is the length of the Burgers vector of the crystal. In order to determine the dislocation density of the sample, symmetric and asymmetric HRXRD RC measurements were conducted and the $\beta^{2}$ of the curves obtained from different planes as a function of $\tan ^{2} \theta$ are plotted in Figure 3. Linear fit to the experimental data presented in Figure 3 gives $K_{\alpha}$ as $86240.12 \operatorname{arcsec}^{2}$ and by using $b=4.33 \AA$ for $\mathrm{Ga}_{0.87} \mathrm{In}_{0.13} \mathrm{As}_{0.04} \mathrm{Sb}_{0.96}$ in Eq. (2), the threading dislocation density was calculated as $\sim 2.5 \times 10^{8} \mathrm{~cm}^{-2}$. Although the large lattice mismatch between $\mathrm{Ga}_{0.87} \mathrm{In}_{0.13} \mathrm{As}_{0.04} \mathrm{Sb}_{0.96}$ and $\mathrm{GaAs}$ substrate, the dislocation density is quite reasonable [15].

In order to understand the electrical properties of the device the voltage dependent dark current measurements were carried out and the dark current density $(\mathrm{J})$ versus voltage curve is presented in Figure 4. From the dark current density curve the $\mathrm{R}_{0} \mathrm{~A}$ value is extracted as $2.34 \Omega . \mathrm{cm}^{2}$ at $300 \mathrm{~K}$ which is an important parameter on the performance of the photodetector. For a better performance of the photodetector $\mathrm{R}_{0} \mathrm{~A}$ value should be as high as possible. On the other hand, there are some limitations that prevent to increase the $\mathrm{R}_{0} \mathrm{~A}$ value such as generation-recombination within the depletion region, tunneling through the depletion region and surface effects [15]. In our case it is believed that the surface effects are the most crucial limitation that effects the performance due to the unpassivated photodetector surface.

To analyze the performance of the photodetector the responsivity measurements were performed and presented in Figure 5. The peak responsivity values are obtained as 0.08 and $0.96 \mathrm{~A} / \mathrm{W}$ under zero and $-100 \mathrm{mV}$ bias at room temperature, respectively. As it is observed, the responsivity of the detector is increased more than an order by applying a reverse bias $(-100 \mathrm{mV})$. To our knowledge, the peak responsivity value obtained under reverse bias is the best value reported up to now for the GaInAsSb detector grown on GaAs. From the responsivity curve it is possible to calculate the cutoff wavelength $\left(\lambda_{c}\right)$ of the photodetector which is defined as the wavelength at which the photodetector response is reduced to $50 \%$ of its peak value. From Figure 5 , the $\lambda_{c}$ value of the photodetector was determined as $\sim 2.15 \mu \mathrm{m}(576 \mathrm{meV})$ at $300 \mathrm{~K}$ under zero bias.

It is well known that $\lambda_{c}$ of a photodetector is related with the band gap energy $\left(\mathrm{E}_{\mathrm{g}}\right)$ of the material. In order to compare the $\lambda_{\mathrm{c}}$ obtained from the responsivity curve, the temperature dependent PL measurements were performed and the PL peak position as a function of temperature is presented in Figure 6. The solid curve in Figure 6 represents a fit to the experimental data by using the Varshni equation [17]

$$
\mathrm{E}(\mathrm{T})=\mathrm{E}(0)-\frac{\alpha \mathrm{T}^{2}}{\mathrm{~T}+\beta}
$$

with the following parameters: $\mathrm{E}(0)=0.61 \mathrm{eV}, \alpha=2.83 \times 10^{-4} \mathrm{meV} / \mathrm{K}$, and $\beta=198.58 \mathrm{~K}$, where $\mathrm{E}(\mathrm{T})$ and $\mathrm{E}(0)$ are the PL emission energy at any temperature $\mathrm{T}$ and $0 \mathrm{~K}$, respectively. From Eq. (3) the bandgap at $300 \mathrm{~K}$ is determined as $557 \mathrm{meV}$ which is very close to the $\lambda_{\mathrm{c}}$ as expected. 
Serincan et al. / Anadolu Univ. J. of Sci. and Technology A-Appl. Sci. and Eng. 18 (3) - 2017

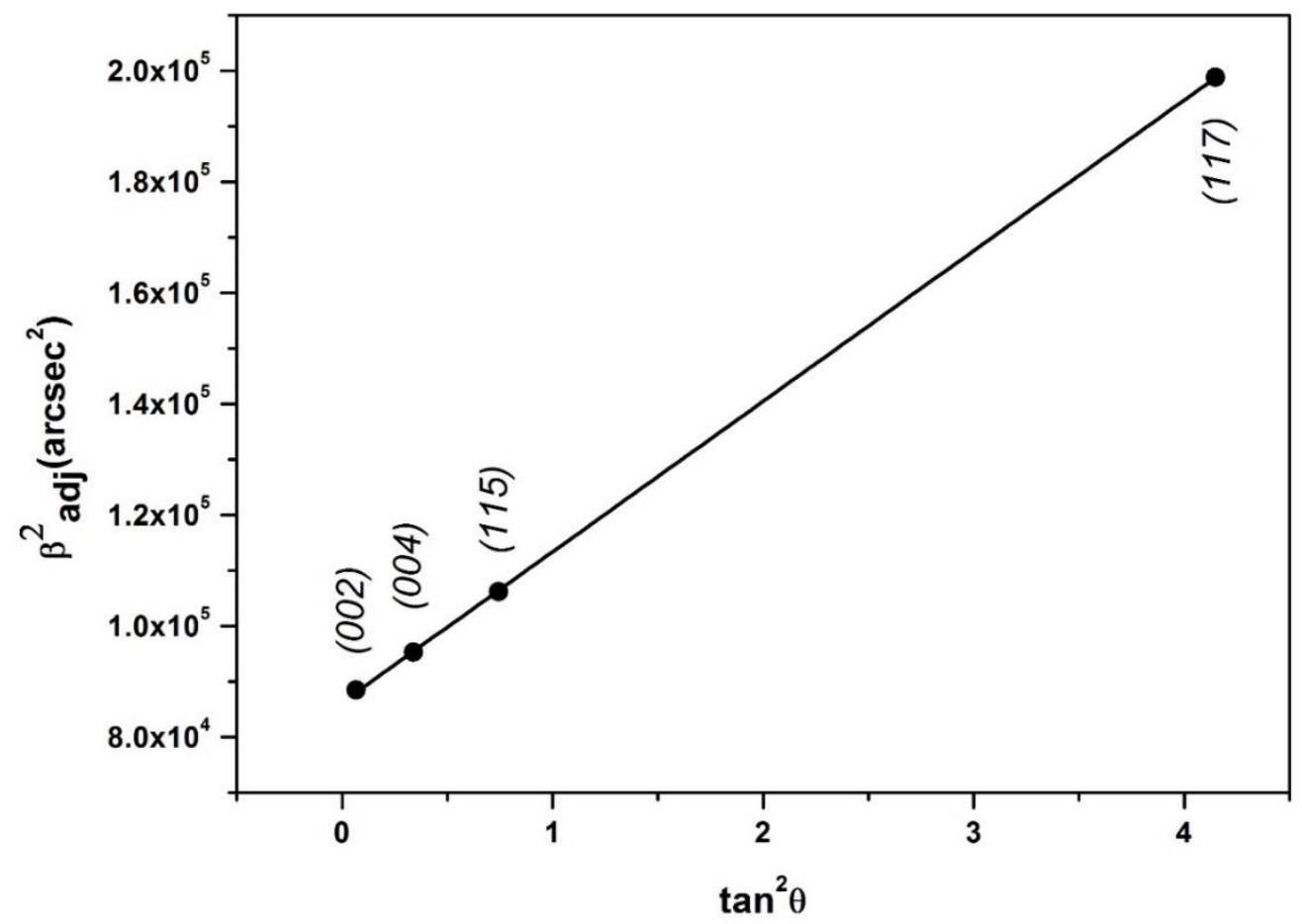

Figure 3. $\beta^{2}$ versus $\tan ^{2} \theta$ plot for $\mathrm{N}_{1}$ and $\mathrm{N}_{2}$. Dots are experimental data and solid line is linear fit

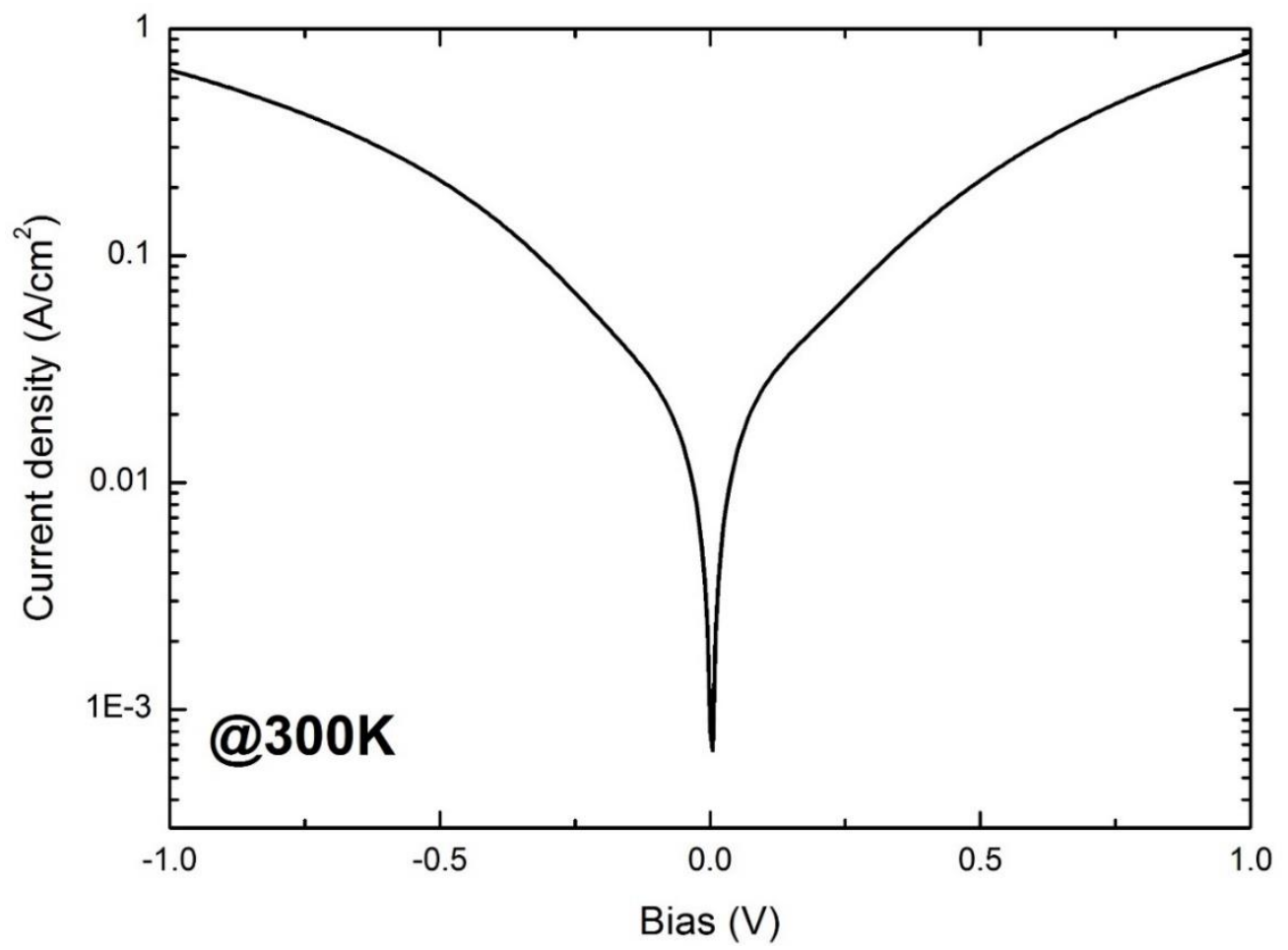

Figure 4. Bias voltage dependence of the dark current density at $300 \mathrm{~K}$ 
Serincan et al. / Anadolu Univ. J. of Sci. and Technology A-Appl. Sci. and Eng. 18 (3) - 2017

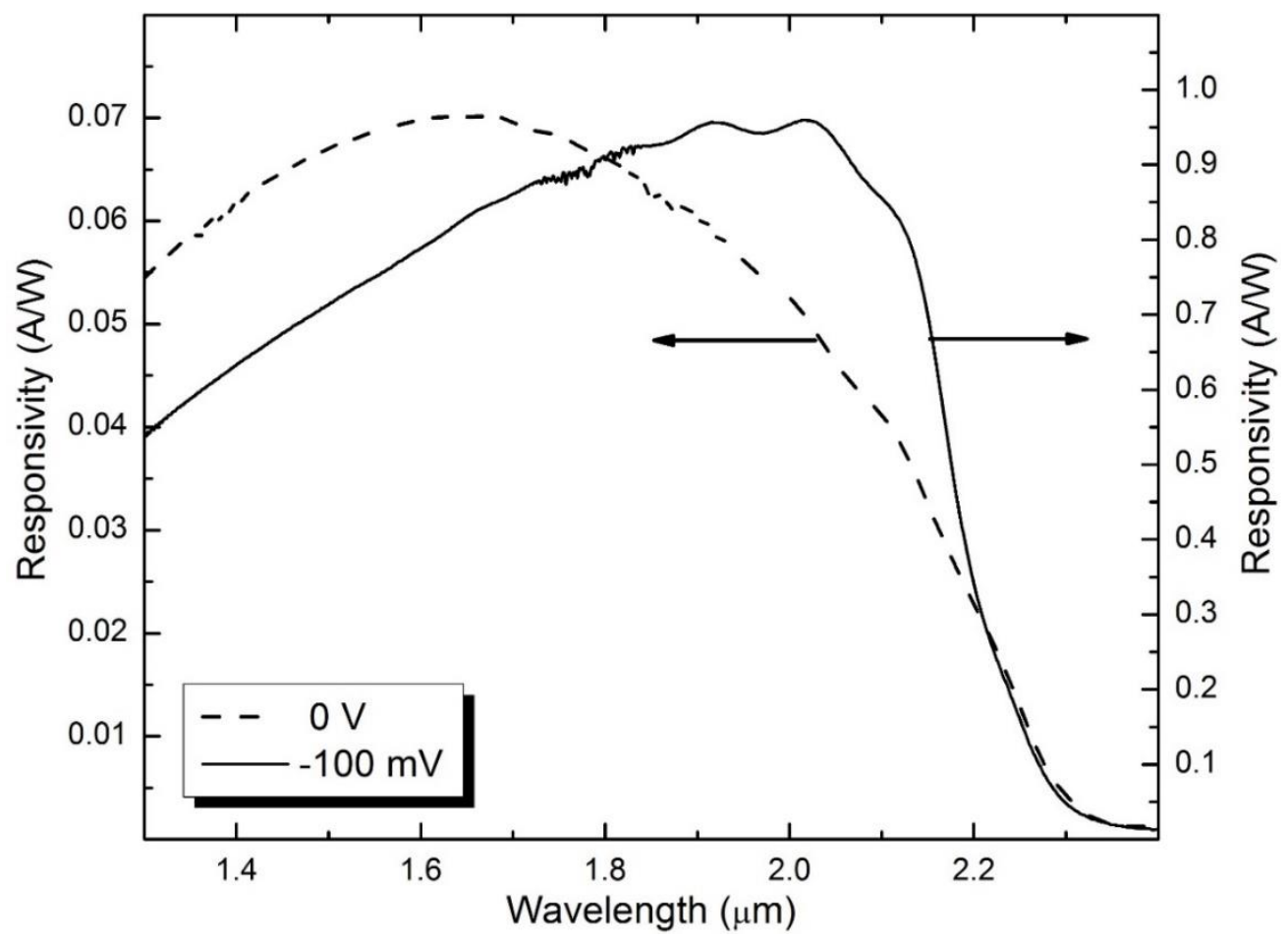

Figure 5. Room temperature responsivity curves of the photodetector under zero bias (dashed curve) and -100 mV (solid line)

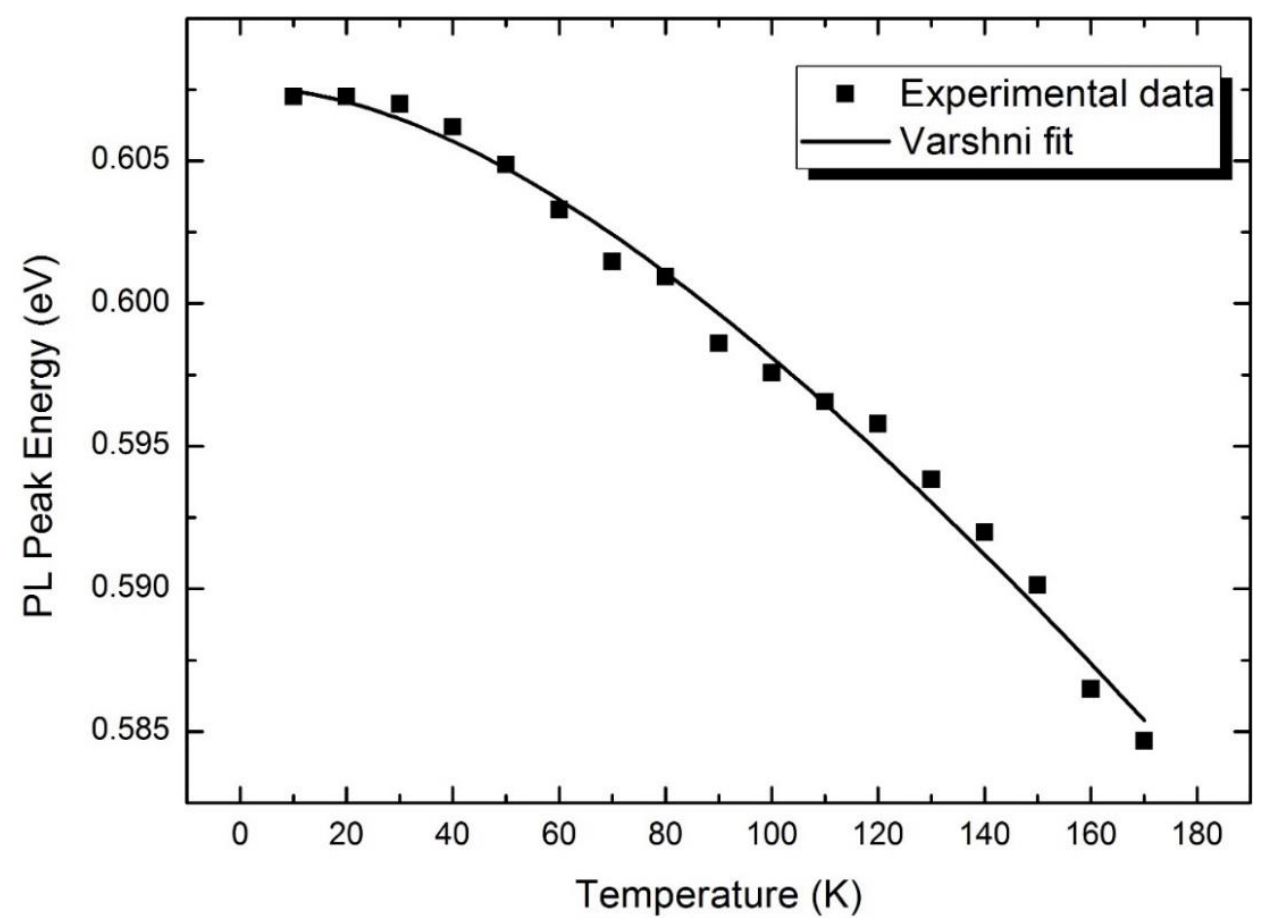

Figure 6. Temperature dependence of the PL peak energies of photodetector structure (solid squares). Solid line is the fitting curve with the Varshni empirical formula. 


\section{CONCLUSIONS}

HRXRD measurements revealed that high crystal quality $\mathrm{Ga}_{0.87} \mathrm{In}_{0.13} \mathrm{As}_{0.04} \mathrm{Sb}_{0.96}$ photodetector structure on GaAs substrate was successfully grown by MBE. Despite the high degree of lattice mismatch, the dislocation density was calculated as $\sim 2.5 \times 10^{8} \mathrm{~cm}^{-2}$ via HRXRD RC measurements which is quite reasonable. The dark current measurements of sample was performed at $300 \mathrm{~K}$ and the $\mathrm{R}_{0} \mathrm{~A}$ value was extracted as $2.34 \Omega . \mathrm{cm}^{2}$ which is acceptable considering the high lattice mismatch between GaInAsSb and GaAs, unpassivated surface of the photodetector and room temperature conditions. Moreover, the $\mathrm{E}_{\mathrm{g}}$ of the sample was monitored by temperature dependent PL and shown that it was in consistent with the $\lambda_{c}$ of the photodetector obtained at $300 \mathrm{~K}$. At room temperature, responsivity value of the $\mathrm{Ga}_{0.87} \mathrm{In}_{0.13} \mathrm{As}_{0.04} \mathrm{Sb}_{0.96}$ photodetector grown on GaAs substrate was determined as $0.96 \mathrm{~A} / \mathrm{W}$ under reverse bias $(-100 \mathrm{mV})$ which is the best value reported up to now. As a consequence, it was demonstrated that by using GaSb transition layer high quality $\mathrm{Ga}_{0.87} \mathrm{In}_{0.13} \mathrm{As}_{0.04} \mathrm{Sb}_{0.96}$ photodetector structure was successfully grown on GaAs substrate by MBE.

\section{ACKNOWLEDGEMENTS}

This work was supported in part by Anadolu University under the project BAP-1301F038.

\section{REFERENCES}

[1] Bergman L, McHale JL. Handbook of luminescent semiconductor materials. 1st ed. New York, CRC Press, 2011, pp.194.

[2] Rogalski A. History of infrared detectors. Opto-Electronics Review 2012; 20: 279-308.

[3] Downs C, Vandervelde TE. Progress in infrared photodetectors since 2000. Sensors (Basel) 2013; 13: 5054-5098.

[4] Martyniuk P, Kopytko M, and Rogalski A. Barrier infrared detectors. Opto-Electronics Review 2014; 22: 127-146.

[5] Gordon NT, Baker IM. Infrared detectors and emitters: materials and devices. 1st ed. United Kingdom: Springer, 2001, pp. 40.

[6] Yildirim A, Prineas JP. Suppressed phase separation in thick GaInAsSb layers across the compositional range grown by molecular beam epitaxy for 1.7-4.9 $\mu \mathrm{m}$ infrared materials J Vac Sci Technol B 2012; 30: 02B104-1-7.

[7] Nunna KC, Tan SL, Reyner CJ, Marshall ARJ, Liang B, Jallipalli A, David JPR, Huffaker DL. Shortwave infrared GaInAsSb photodiodes grown on GaAs substrate by interfacial misfit array technique. IEEE Photonics Tech L 2012; 24: 218-220.

[8] Wang CA, Choi HK, Oakley DC, Charache GW. Recent progress in GaInAsSb thermophotovoltaics grown by organometallic vapor-phase epitaxy. J Cryst Growth 1998; 195, 346-355.

[9] Lei L, Li L, Lotfi H, Jiang Y, Yang RQ, Johnson MB, Lubyshev D, Qiu Y, Fastenau JM, Liu AWK. Mid-wave interband cascade infrared photodetectors based on GaInAsSb absorbers. Semicond Sci Technol 2016; 31: 105014-1-7.

[10] Reddy MHM, Olesberg JT, Cao C, Prineas JP. MBE-grown high-efficiency GaInAsSb mid-infrared detectors operating under back illumination. Semicond Sci Technol 2006; 21: 267-272. 
Serincan et al. / Anadolu Univ. J. of Sci. and Technology A-Appl. Sci. and Eng. 18 (3) - 2017

[11] Bracker AS, Yang MJ, Bennett BR, Culbertson JC, Moore WJ. Surface reconstruction phase diagrams for InAs, AlSb and GaSb. J Cryst Growth 2000; 220: 384-392.

[12] Erkus M, Senel O and Serincan U. Structural, optical and electrical characterization of $\operatorname{InAs} \mathrm{As}_{0.83} \mathrm{Sb}_{0.17}$ p- $\pi$-n photodetector grown on GaAs substrate. Thin Solid Films 2016; 616: 141-144.

[13] Deng HY, Hong XK, Fang WZ, Dai N. Microstructure characterization of InAs $\mathrm{s}_{0.93} \mathrm{Sb}_{0.07}$ films grown by ramp-cooled liquid phase epitaxy. Mater Charact 2007; 58: 307-311.

[14] Ayers JE. The measurement of threading dislocation densities in semiconductor crystals by X-ray diffraction. J Cryst Growth 1994; 135: 71-77.

[15] Wang G, Loo R, Simoen E, Souriau L, Caymax M, Heyns MM, Blanpain B. A model of threading dislocation density in strain-relaxed Ge and GaAs epitaxial films on Si (100). Appl Phys Lett 2009; 94: 102115-1-3.

[16] Rogalski A. HgCdTe infrared detector material: history, status and outlook. Rep Prog Phys 2005, $68,2267-2336$.

[17] Varshni YP. Temperature dependence of the energy gap in semiconductors. Physica 1967; 34: 149154. 